\title{
Inhibition of the interleukin-23/interleukin-17 pathway by anti-interleukin-23p19 monoclonal antibody attenuates 2,4,6-trinitrobenzene sulfonic acid-induced Crohn's disease in rats
}

\author{
JIA YIN YAO ${ }^{1}$, YI LU ${ }^{2}$, MIN ZHI $^{1}, \mathrm{CHU}_{\text {JUN LI }}{ }^{1}$, PIN JIN HU ${ }^{1}$ and XIANG GAO ${ }^{1}$ \\ ${ }^{1}$ Department of Gastroenterology, The Sixth Affiliated Hospital of Sun Yat-Sen University, Guangzhou, Guangdong 510655; \\ ${ }^{2}$ Department of Anesthesiology, Guangzhou Hospital of Traditional Chinese Medicine, \\ Guangzhou, Guangdong 510130, P.R. China
}

Received January 29, 2014; Accepted June 24, 2014

DOI: $10.3892 / \mathrm{mmr} .2014 .2427$

\begin{abstract}
The interleukin (IL)-23/IL-17 pathway is considered to be important in the pathogenesis of Crohn's disease (CD). The present study aimed to evaluate the effects of targeting the IL-23/IL-17 pathway using the anti-IL-23p19 monoclonal antibody (mAb) on 2,4,6-trinitrobenzene sulfonic acid (TNBS)-induced CD rats. A total of 60 Sprague-Dawley rats were randomly divided into a control group, model group and an anti-IL-23p19 mAb treatment group (administered intramuscularly every week at a dose of $1 \mathrm{ml} / \mathrm{mg}$ ). Disease activity index (DAI), colon macroscopic damage index (CMDI) and tissue damage index (TDI) were then evaluated. The mRNA expression of IL-23p19, p40 (IL-23/12), retinoic acid-related orphan receptor- $\gamma \mathrm{t}(\mathrm{ROR}-\gamma \mathrm{t})$ and IL-17 in colonic tissues were detected by reverse transcription-polymerase chain reaction and levels of serum IL-23p19, p40, ROR- $\gamma$ t and IL-17 were measured using an enzyme-linked immunosorbent assay. Anti-IL-23p19 mAb was found to effectively attenuate colonic inflammation demonstrated by reduced DAI, CMDI and TDI scores, improvement in pathological evaluation and downregulation of expression levels of IL-23p19, p40 (IL-23/12), ROR- $\gamma \mathrm{t}$ and the downstream proinflammatory cytokine, IL-17. Anti-IL-23p19 mAb attenuated TNBS-induced CD in model rats. The possible underlying mechanisms may be associated with inhibition of the IL-23/IL-17 pathway by inhibiting the expression of IL-23p19 and downregulating the downstream proinflammatory cytokine IL-17. Targeting the IL-23/IL-17
\end{abstract}

Correspondence to: Professor Xiang Gao, Department of Gastroenterology, The Sixth Affiliated Hospital of Sun Yat-Sen University, 26 Yuancun Erheng Road, Guangzhou, Guangdong 510655, P.R. China

E-mail: doctorgaoxiang@yeah.net

Key words: interleukin-23/interleukin-17, Crohn's disease, anti-interleukin-23p19 monoclonal antibody, target therapy pathway may be a relevant and realistic therapeutic approach for the development of additive and alternative treatments to the biologics currently available in the treatment of CD.

\section{Introduction}

Crohn's disease (CD) is a chronic relapsing inflammatory disorder of the gastrointestinal tract. Although the mechanisms underlying the pathogenesis of CD are not fully understood, humoral and cellular immunity are known to be involved (1).

A new member of the interleukin (IL)-12 cytokine family, produced mainly by dendritic cells and activated macrophages, was termed IL-23 in 2000 (2). It consists of two subunits: p40, which is shared by IL-12, and p19, which is specific to IL-23. Numerous pathological defects found in animal models of autoimmunity were initially associated with IL-12, but are now understood to be caused by IL-23 $(3,4)$. For example, inactivation of the IL-23p19 gene imparts resistance to experimental allergic encephalomyelitis and collagen-induced arthritis in rats, whereas rats deficient in IL-12p35 are sensitized to these diseases (5). Furthermore, IL-23 was found to be overexpressed in the intestine of patients with $\mathrm{CD}$, indicating a correlation between disease activity and the levels of IL-23 in $\mathrm{CD}(6)$.

IL-23 was demonstrated to induce the differentiation of naïve T CD4 lymphocytes into T helper 17 (Th17) cells, causing overexpression of the transcription factor retinoic acid-related orphan receptor- $\gamma \mathrm{t}(\mathrm{ROR}-\gamma \mathrm{t})$ and production of IL-17, and was negatively regulated by $\mathrm{TNF}-\gamma$ (7-9). The proinflammatory cytokine IL-17 resulted in the production of other cytokines and created a positive feedback loop for Th17 inflammation. The IL-23/IL-17 pathway is considered to be important in the pathogenesis of CD $(10,11)$.

Over the last decade, the use of cytokine antagonists, including monoclonal antibodies and soluble receptors, has become a clinical standard for the treatment of autoimmune disease, as illustrated by the use of anti-TNF- $\alpha$ antagonists in CD $(12,13)$. In light of the suspected effect of IL-23 on the development of $\mathrm{CD}$, the present study evaluated the efficacy of 
an immunization specifically targeting the IL-23p19 subunit in a CD rat model induced by 2,4,6-trinitrobenzene sulfonic acid (TNBS).

\section{Materials and methods}

Ethics statement. All experiments were performed in conformity with the National Institute of Health $(\mathrm{NIH})$ guidelines (NIH Pub. no. 85-23, revised 1996) and the Animal Research Reporting In Vivo Experiments guidelines (14) and approved by the Animal Care and Use Committee of Sun Yat-Sen University (Gangzhou, China; no. 20131652101). All surgical and experimental procedures were performed according to the guidelines for the care and use of animals approved by the Sun Yat-Sen University and in accordance with the code of Ethics of the EU Directive 2010/63/EU for animal experiments. All efforts were made to minimize animal suffering and to reduce the number of animals used.

Animals. A total of 60 specific pathogen-free male Sprague Dawley rats (6-weeks-old, weighing 180-220 g), were obtained from the Animal Experiment Center of the Sun Yat-Sen University. Animals were housed in 12 cages with five rats each and were maintained in a 12:12 h artificial light-dark cycle. All experiments were performed in the city of Guangzhou, China.

Method. After 1 week habituation, 60 Sprague Dawley rats were randomly divided into three groups of 20 rats each: control group, CD model group and anti-IL-23p19 mAb treatment group. The $\mathrm{CD}$ rat models were induced by rectal administration of TNBS (Sigma, St. Louis, MO, USA; no. 068K5001)/ethanol (TNBS $100 \mathrm{mg} / \mathrm{kg}+0.25 \mathrm{ml} 50 \%$ ethanol), performed four times at 10 day intervals (days 0 , 10, 20 and 30) (15). Anti-IL-23p19 mAb (RayBiotech, Inc., Norcross, GA, USA; no: PAB1106) was administered intramuscularly $(1 \mathrm{mg} / \mathrm{kg})$ every week at days $0,7,14,21,28$ and 35 . Rats in the control group and in the model group received rectal administration of $0.9 \%$ sodium chloride solution $(0.1 \mathrm{mg} / \mathrm{kg})$.

Necropsy. At the end of the experiment (day 40), rats were anesthetized and blood samples were collected into tubes by cardiac puncture for enzyme-linked immunosorbent assay (ELISA). Colon tissue specimens were assessed macroscopically prior to being excised and fixed in 10\% formaldehyde saline solution for histological analysis. The remaining tissue was snap-frozen in liquid nitrogen and stored at $-80^{\circ} \mathrm{C}$ for reverse transcription polymerase chain reaction (RT-PCR) detection.

Disease activity index (DAI) of rats. Symptomatic parameters were observed and recorded daily during the experimental period. Stools were assessed for occult blood using the colloidal gold method and a fecal occult blood test kit (Shanghai Sunred Biological Technology Co., Ltd., Shanghai, China). DAI was determined in a blinded manner by scoring the extent of body weight loss, stool consistency and stool occult blood positivity or gross bleeding in accordance with the method described by Murthy et al (16). The results are shown in Table I.
Table I. Criteria for scoring disease activity index.

\begin{tabular}{llll}
\hline Score & $\begin{array}{l}\text { Weight } \\
\text { loss }(\%)\end{array}$ & $\begin{array}{c}\text { Stool } \\
\text { consistency }\end{array}$ & $\begin{array}{c}\text { Occult blood or } \\
\text { gross bleeding }\end{array}$ \\
\hline 0 & None & Normal & Negative \\
1 & $1-5$ & Loose & Negative \\
2 & $5-10$ & Loose & Hemoccult positive \\
3 & $10-15$ & Diarrhea & Hemoccult positive \\
4 & $>15$ & Diarrhea & Gross bleeding \\
\hline
\end{tabular}

Disease activity index $=($ combined score of weight loss + stool consistency + bleeding) / 3. Normal stools, well-formed pellets; loose stool, pasty stools that do not stick to the anus; diarrhea, liquid stools that stick to the anus.

Colon macroscopic damage index (CMDI) of rats. The distal $8 \mathrm{~cm}$ portion of the colon was excised, opened longitudinally and thoroughly washed in ice-cold phosphate-buffered saline (PBS; Qiagen, Valencia, CA, USA). The CMDI was determined according to the scoring system of Wallace and Keenan $(17,18)$. The criteria for assessing macroscopic damage and the numerical rating score were as follows: 0 , no ulcer or inflammation; 1 , local hyperemia without ulcers; 2 , ulceration without hyperemia; 3 , ulceration and inflammation at one site only; 4 , two or more sites of ulceration and inflammation extending $>1 \mathrm{~cm}$ and 5 , ulceration extending $>2 \mathrm{~cm}$ (19).

Tissue damage index (TDI) of rats. The specimens of colon tissue were stained with hematoxylin and eosin for evaluation of liver histology. The TDI of the stained samples was evaluated in a blinded manner according to the previously described criteria $(20,21)$ between 0 and 4 ( 0 , no signs of inflammation; 1 , low level of leukocyte infiltration; 2 , moderate level of leukocyte infiltration; 3 , high level of leukocyte infiltration, high vascular density, thickening of the colon wall; 4 , on the basis of score 3 , the lesions exceed $50 \%$ of the specimens; 5 , transmural infiltration, loss of goblet cells, high vascular density, thickening of the colon wall; 6 , on the basis of score 5 , the lesions exceed $50 \%$ of the specimens).

Isolation of total RNA and RT-PCR analysis. All rats in each group were sampled for RT-PCR analysis. Total RNA was extracted from the colon tissue using TRIzol (Qiagen) according to the manufacturer's instructions. Total RNA (500 ng) was used for cDNA synthesis and $1 \mu 1$ of each reverse transcription product was added to $9 \mu 1$ Master mix [containing buffer, SYGB, Hotstart Taq polymerase and deoxyribonucleotide triphosphates (dNTPs), purchased from Qiagen], $0.2 \mu \mathrm{l} 25 \mathrm{mM}$ dNTPs, $0.5 \mu 125 \mu \mathrm{M}$ corresponding primers and $9.3 \mu 1 \mathrm{ddH}_{2} \mathrm{O}$ (Qiagen) for PCR amplification. The number of cycles, annealing temperature for each primer pair and primer sequences used are listed in Table II. The relative levels of target mRNA were normalized to the corresponding levels of GAPDH mRNA in the same cDNA sample using the standard curve method recommended in the LightCycler Software, version 3.5 (Roche Molecular Diagnostics Systems, Meylan, France). 
Table II. Primers and product size for each target gene.

\begin{tabular}{|c|c|c|c|c|}
\hline Gene & Primer & $\begin{array}{l}\text { Length } \\
\text { (bp) }\end{array}$ & Cycles & $\begin{array}{l}\text { Annealing } \\
\text { temp }\left({ }^{\circ} \mathrm{C}\right)\end{array}$ \\
\hline IL-23p19 & $\begin{array}{l}\text { Forward: 5'-GAATCTGGTGGCTGTGGA-3' } \\
\text { Reverse: 5'-CCCTGAAAGGCTTGGTCT-3' }\end{array}$ & 230 & 35 & 52 \\
\hline p40 (IL-23/12) & $\begin{array}{l}\text { Forward: 5'-GATTATGTGGAGTCTGGA-3' } \\
\text { Reverse: 5'-CTAAGACACCTCAGACCT-3' }\end{array}$ & 278 & 35 & 52 \\
\hline ROR- $\gamma \mathrm{t}$ & $\begin{array}{l}\text { Forward: 5'-CGTATTACGGATAACCGACG-3' } \\
\text { Reverse: 5'-GCATAATGCCTATTGGCTGC-3' }\end{array}$ & 266 & 38 & 52 \\
\hline Th17 & $\begin{array}{l}\text { Forward: 5'-CATCAGCTACATGCATTCC-3' } \\
\text { Reverse: 5'-GTAGTCGATGTACGTAAGG-3' }\end{array}$ & 253 & 35 & 52 \\
\hline IL-17 & $\begin{array}{l}\text { Forward: 5'-GCAATGGCCTATACGCCATC-3' } \\
\text { Reverse: 5'-CGTTACCGGATATGCGGTAG-3' }\end{array}$ & 233 & 33 & 52 \\
\hline GAPDH & $\begin{array}{l}\text { Forward: 5'-GAATCTGGTGGCTGTGGA-3' } \\
\text { Reverse: 5'-CCCTGAAAGGCTTGGTCT-3' }\end{array}$ & 207 & 35 & 52 \\
\hline
\end{tabular}

IL, interleukin; ROR- $\gamma \mathrm{t}$, retinoic acid-related orphan receptor- $\gamma \mathrm{t}$; TH17, T helper 17; temp, temperature.

ELISA analysis of levels of cytokines in the serum. The levels of cytokines IL-23p19, p40 (IL-23/12), ROR- $\gamma$ t and IL-17 in the serum were measured using ELISA kits (R\&D Systems, Minneapolis, MN, USA) according to the manufacturer's instructions. A standard curve was generated with each assay with the limits of detection as follows: IL-23p19, $12 \mathrm{pg} / \mathrm{ml}$; $\mathrm{p} 40$ (IL-23/12), $15 \mathrm{pg} / \mathrm{ml}$; ROR- $\gamma \mathrm{t}=6.1 \mathrm{pg} / \mathrm{ml}$ and IL-17 $=3.0 \mathrm{pg} / \mathrm{ml}$. Each sample was performed in triplicate.

Statistical analysis. Data are expressed as the mean \pm standard deviation. Data were analyzed by one-way analysis of variance (ANOVA), followed by the Bonferroni multiple comparisons test. The statistical significance of the expression analysis was also assessed by ANOVA and the differences identified were assessed using the unpaired Student's t-test. $\mathrm{P}<0.05$ was considered to indicate a statistically significant difference. All statistical analyses were performed using SPSS version 13.0 (SPSS, Inc., Chicago, IL, USA).

\section{Results}

DAI scores of rats in each group. DAI, representing symptomatic parameters, including diarrhea and loss of body weight, was investigated. Rats in the normal control group gained body weight and defecated normally. As shown in Fig. 1, following induction of CD by administration of TNBS, pasty to liquid, gross blood stools and weight loss were observed with higher DAI scores in CD model rats $(\mathrm{P}<0.001$, vs. control group). However, the DAI scores markedly decreased following treatment with anti-IL-23p19 mAb ( $\mathrm{P}<0.005$, vs. model group).

Pathological alterations in rat colon tissue in each group. The colon tissue from the CD model rats induced by TNBS was characterized by epithelial hyperplasia and infiltration of the lamina propria with inflammatory cells, including a large number of neutrophils (Fig. 2B). Epithelioid granuloma (Arrow,

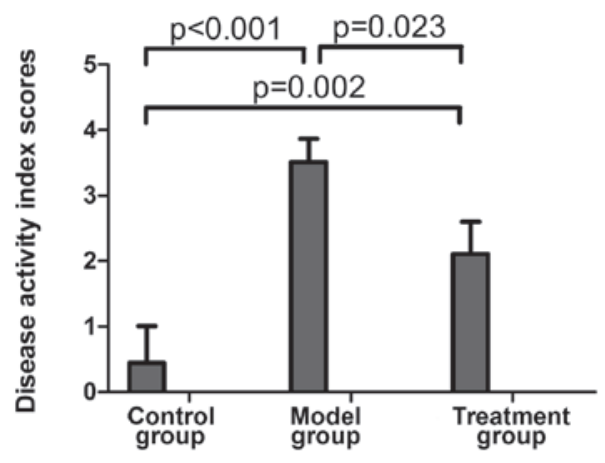

Figure 1. Disease activity index scores of rats in each group (analysis of variance followed by Bonferroni multiple comparisons test). Data are expressed as the mean \pm standard deviation.

Fig. 2B) and crypt abscesses (Arrows, Fig. 2E) were also frequently observed. Following treatment with anti-IL-23p19 $\mathrm{mAb}$, the inflammation present within the colon tissue typically involved the mucosa only, with little to no inflammation present in the submucosa, demonstrating a marked improvement in inflammation (Fig. 2C and F).

CMDI and TDI were used to assess the degree of colonic inflammation. The CMDI and TDI were significantly higher in the model group compared with the control group $(\mathrm{P}<0.01)$. The anti-IL-23p19 mAb treatment group demonstrated a marked reduction in CMDI and TDI scores compared with the model group $(\mathrm{P}<0.05)$, indicating that the macroscopical and microscopical lesions reduced following drug intervention (Fig. 3).

Expression of cytokines in colon tissue detected by RT-PCR. A significant increase in all cytokines [IL-23p19, p40 (IL-23/12), ROR- $\gamma$ t and IL-17] was observed in the CD model group induced by TNBS $(\mathrm{P}<0.001)$. The expression of IL-23p19 $(\mathrm{P}=0.002)$ and IL-17 $(\mathrm{P}=0.003)$ was inhibited following 

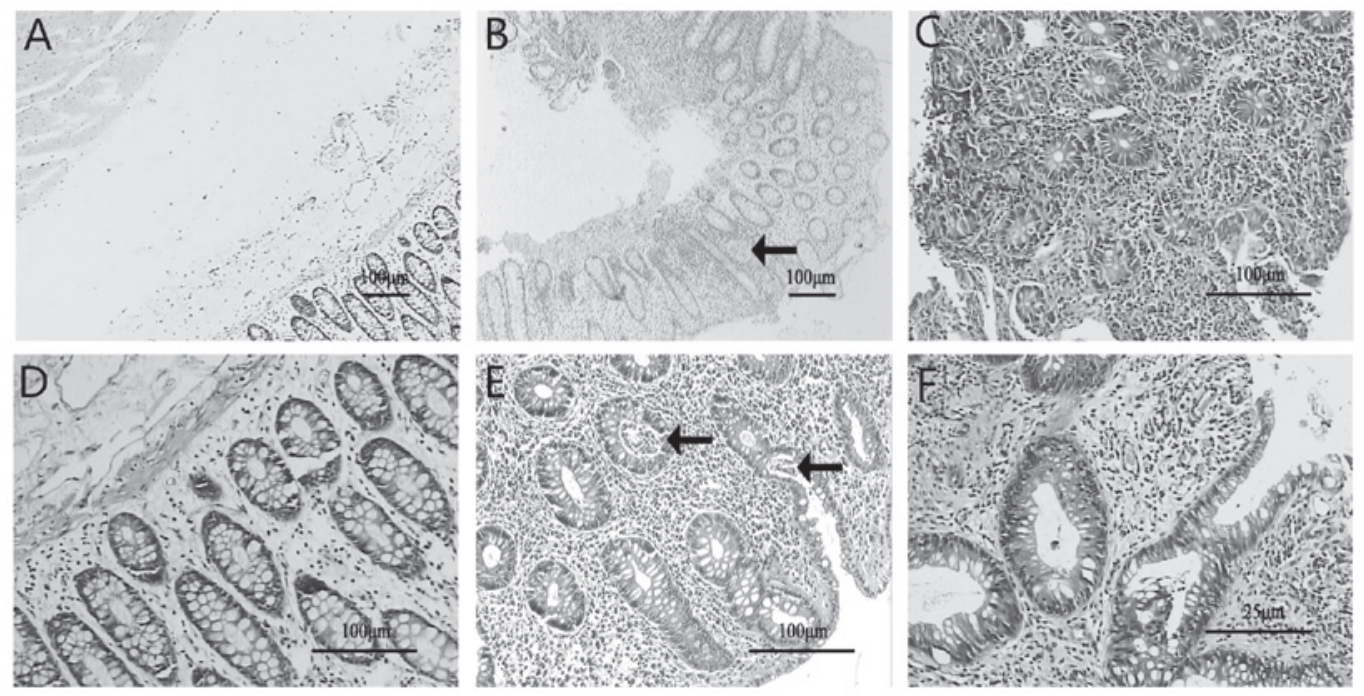

Figure 2. Pathological alterations in the rat colon stained with hematoxylin and eosin in each group. (A and B) Low magnification, x40. (C-E) High magnification, x100. (F) High magnification, x400. (A and D) Colonic tissues in the control group with integrated architecture demonstrating mild or no inflammation (B and E) Colonic tissues in the Crohn's disease model group induced by 2,4,6-trinitrobenzene sulfonic acid demonstrating a thickened bowel wall, marked inflammatory cell infiltration and epithelioid granulomas. Typical crypt abscesses indicated by arrows. (C and F) Colonic tissues in the treatment group exhibiting improvement in inflammation with reduced inflammatory cell infiltration.

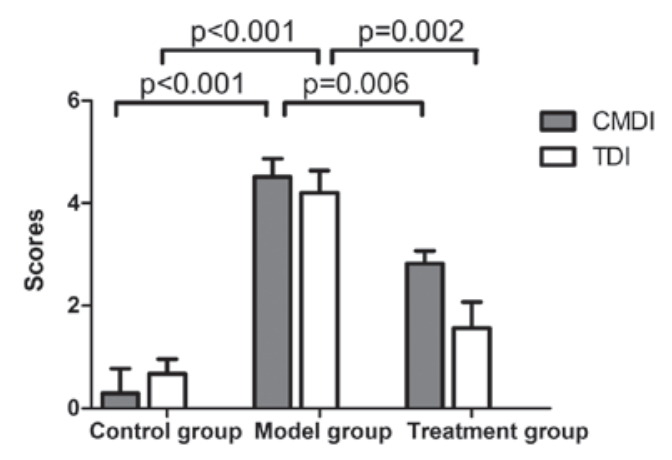

Figure 3. Evaluation of CMDI and TDI scores in each group (analysis of variance test followed by Bonferroni multiple comparisons test). Data are expressed as the mean \pm standard deviation. CDMI, colon mucosal damage index; TDI, tissue damage index.

administration of anti-IL-23p19 mAb as a targeted therapy. There was also a decrease in the expression of p40 (IL23/12) and ROR- $\gamma \mathrm{t}$ in the treatment group compared with the model group, however, this was not statistically significant (Fig. 4).

Serum cytokines in each group detected by ELISA. The concentration of secreted serum cytokines of rats in each group was measured using ELISA. A significant increase in IL-23p19, P40 (IL-23/12), ROR- $\gamma \mathrm{t}$ and IL-17 content was observed in the model group compared with the control group. A significant decrease in the concentration of IL-23p19 and IL-17 was observed in the treatment group (Fig. 5).

\section{Discussion}

The TNBS model of experimental CD is a well established model of chronic colonic inflammation and ulceration in rats, which is characterized by transmural inflammation associated with severe diarrhea and histopathological features that resemble the immune characteristics of $\mathrm{CD}$ in humans $(22,23)$.
It has been used extensively in the evaluation of new therapeutic strategies for human cases of CD since Morris' preliminary description in 1989 (15). The present study successfully established CD rat models induced by TNBS. This was confirmed by the observation of pathological changes, including extensive transmural infiltration of inflammatory cells, thickening of the colon wall and formation of typical epithelioid granulomas and crypt abscesses. Furthermore, the model rats demonstrated a marked increase in CMDI, TDI and DAI scores, indicating the presence of severe colonic damage at the macroscopic and microscopic levels and clinical symptoms. Disorders in the expression of cytokines in the IL-23/IL-17 pathway were also observed in the model rats, revealing the importance of cytokines in the pathogenesis of $\mathrm{CD}$.

Currently, an effective therapy for patients with $\mathrm{CD}$ is lacking. Aminosalicylates, corticosteroids and immunomodulating drugs have multiple adverse effects and a high relapse percentage $(24,25)$. Biological agents, including anti-TNF- $\alpha$ $\mathrm{mAb}$ may induce the alleviation of inflammatory bowel disease (26), but at a high cost and with an increased risk to patients in developing treatment-associated cancer $(27,28)$. The ultimate alternative is often surgical resection of the colon and ileostomy (29). Therefore, there is a continuing interest in novel therapeutic approaches for controlling $\mathrm{CD}$, thus the present study focused on targeted therapy using anti-IL-23p19 $\mathrm{mAb}$. The present study demonstrated that the administration of anti-IL-23p19 mAb effectively attenuated colonic inflammation induced by TNBS in rats and significantly reduced DAI, CMDI and TDI scores. Pathological evaluation of colon tissue demonstrated improvements in inflammation with a reduction in inflammatory cell infiltration. The above revealed a favorable efficacy of anti-IL-23p19 mAb in curing TNBS-induced $\mathrm{CD}$ in rats.

The results from the present study demonstrated a marked increase in the expression of IL-23p19, p40 (IL-23/12), ROR- $\gamma \mathrm{t}$ and the downstream cytokine IL-17 in CD rats, indicating 
A
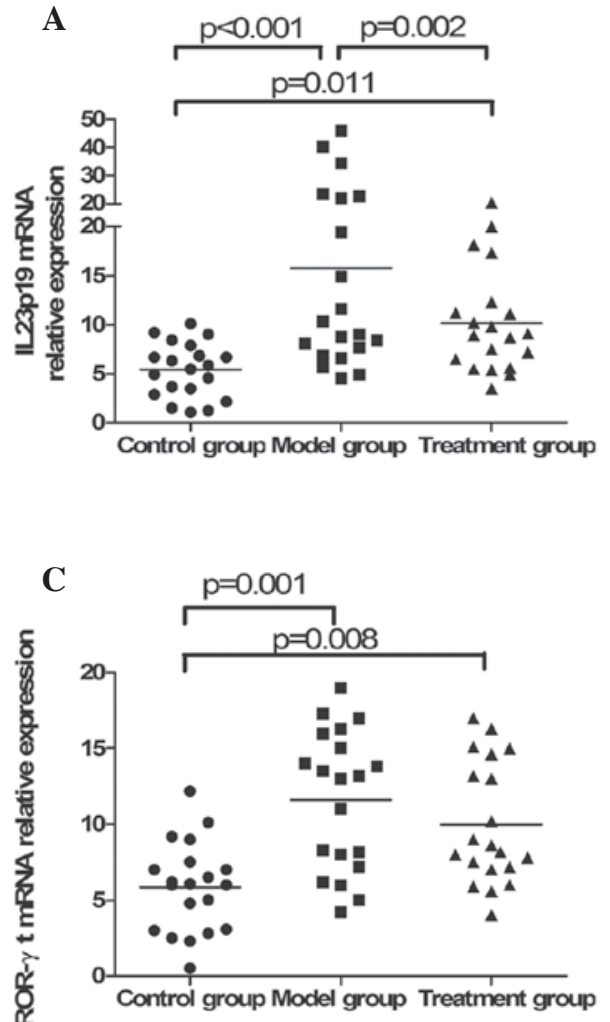
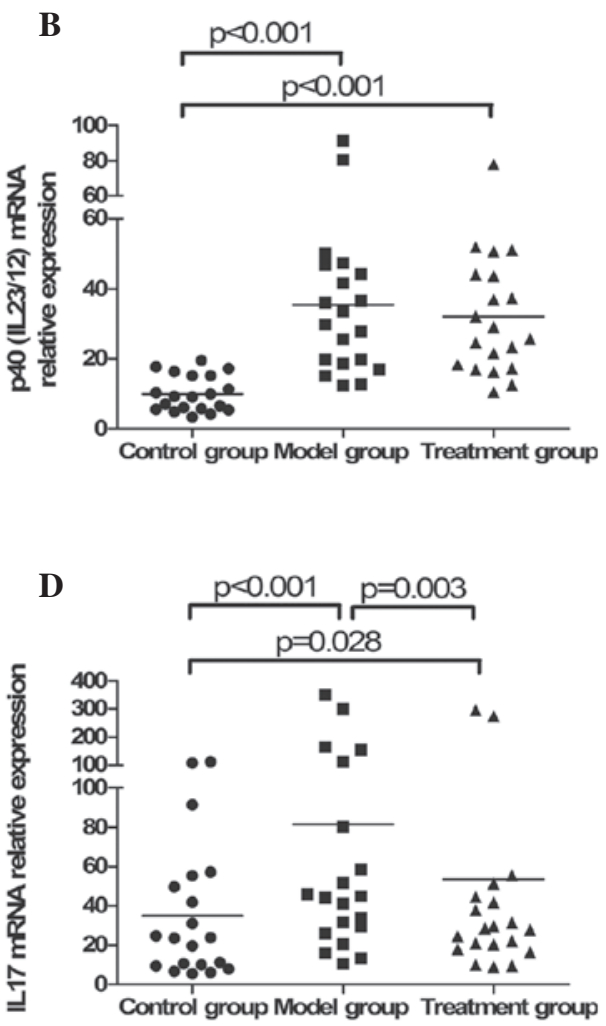

Figure 4. Relative expression of cytokines in each group. Relative expression of each cytokine was analyzed in the colon samples obtained from rats in each group by reverse transcription polymerase chain reaction and normalized to GAPDH. Data are presented as individual cytokine values in single biopsies and horizontal bars represent the median value. IL, interleukin; ROR- $\gamma$ t, retinoic acid-related orphan receptor- $\gamma \mathrm{t}$.

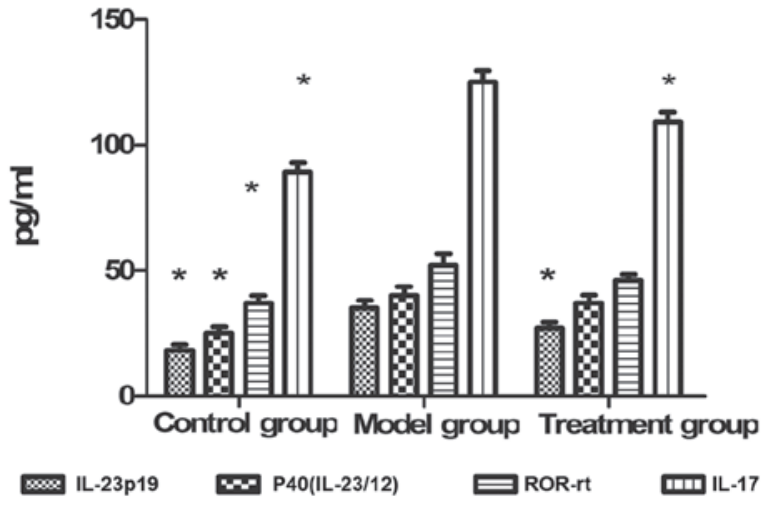

Figure 5. Concentration of cytokines in each group detected by enzyme-linked immunosorbent assay. Data are expressed as the mean \pm standard deviation $(\mathrm{n}=20) .{ }^{*} \mathrm{P}<0.05$, vs. model group. IL, interleukin; ROR- $\gamma \mathrm{t}$, retinoic acid-related orphan receptor- $\gamma \mathrm{t}$.

that the IL-23/IL-17 pathway was important in the pathogenesis of $\mathrm{CD}$. The present study focused on the efficacy of targeted therapy by inhibition of the IL-23/IL-17 pathway using anti-IL-23p19 mAb. As expected, anti-IL-23p19 mAb effectively inhibited the expression of IL-23p19 and the proinflammatory cytokine IL-17, however, no significant effect on the expression of p40, the common subunit shared by IL-23 and IL-12, was observed. The results of the present study verified the hypothesis that IL-23, not IL-12, is associated with autoimmune disease. The expression of serum cytokines detected by ELISA demonstrated similar results. Notably, regulation of the expression of ROR- $\gamma \mathrm{t}$, considered to be a key transcription factor in the differentiation of Th17 cells and regulation of IL-17 expression in vivo and in vitro, was not affected by anti-IL-23p19 mAb. ROR- $\gamma$ t knockout mice demonstrated a reduction in Th17 cells and in the incidence of autoimmune diseases $(30,31)$. In the present study, intervention by anti-IL-23p19 mAb was associated with a decrease in ROR- $\gamma \mathrm{t}$, although this was not considered to be statistically significant. This indicated that anti-IL-23p19 mAb may inhibit the differentiation of Th17 through the mediator ROR- $\gamma \mathrm{t}$. The detailed and specific pathway of anti-IL-23p19 mAb in treating $\mathrm{CD}$ model rats therefore requires further investigation.

IL-12 and IL-23 are members of a heterodimeric cytokine family, which share a common IL-12p40 subunit $(2,32,33)$. IL-12 is the driving force behind Th1 inflammation, while IL-23 maintains the effector function of Th17 cells $(34,35)$. In 2009, a biological drug termed ustekinumab, which targets the p40 subunit of IL-12 and IL-23, was developed and approved by the US FDA and the European Medicines Agency for the treatment of moderate to severe psoriasis. However, the high incidence of adverse events (51.6-57.6\%) restricted its application in CD patients $(36,37)$. The present study focused on another targeted therapy using anti-IL-23p19 mAb. In the rats administered with anti-IL-23p19 mAb, a reduction in colon pathology and improved clinical symptoms were observed compared with the model rats. In addition, no mortality or serious adverse reactions were observed in the rats treated with anti-IL-23p19 mAb. However, as the prevention of CD was incomplete, the results suggested that there may have been a dosing and/or timing issue associated with the therapeutic effectiveness of anti-IL-23p19 mAb treatment. 
In conclusion, the present study demonstrated that anti-IL-23p19 mAb attenuated TNBS-induced CD in rats. The possible mechanisms may be associated with inhibition of the IL-23/IL-17 pathway by inhibiting the expression of IL-23p19 and downregulating the downstream proinflammatory cytokine IL-17. Anti-IL-23p19 mAb as a new targeted therapy may provide a novel therapeutic approach for patients with $C D$, however, this requires further investigation.

\section{Acknowledgements}

The present study was supported by a grant from the Medical Research Foundation of Guangdong, China (no. B2013159) to Jiayin Yao.

\section{References}

1. Geremia A, Biancheri P, Allan P, Corazza GR and Di Sabatino A Innate and adaptive immunity in inflammatory bowel disease. Autoimmun Rev 13: 3-10, 2013.

2. Oppmann B, Lesley R, Blom B, et al: Novel p19 protein engages IL-12p40 to form a cytokine, IL-23, with biological activities similar as well as distinct from IL-12. Immunity 13: 715-725, 2000.

3. Cua DJ, Sherlock J, Chen Y, et al: Interleukin-23 rather than interleukin-12 is the critical cytokine for autoimmune inflammation of the brain. Nature 421: 744-748, 2003.

4. Vignali DA and Kuchroo VK: IL-12 family cytokines: immunological playmakers. Nat Immunol 13: 722-728, 2012.

5. Duvallet E, Semerano L, Assier E, Falgarone G and Boissier MC: Interleukin-23: a key cytokine in inflammatory diseases. Ann Med 43: 503-511, 2011.

6. Duerr RH, Taylor KD, Brant SR, et al: A genome-wide association study identifies IL23R as an inflammatory bowel disease gene. Science 314: 1461-1463, 2006.

7. McGeachy MJ, Chen Y, Tato CM, et al: The interleukin 23 receptor is essential for the terminal differentiation of interleukin 17-producing effector $\mathrm{T}$ helper cells in vivo. Nat Immunol 10: 314-324, 2009.

8. Rovedatti L, Kudo T, Biancheri P, et al: Differential regulation of interleukin 17 and interferon gamma production in inflammatory bowel disease. Gut 58: 1629-1636, 2009.

9. Sarra M, Pallone F, Macdonald TT and Monteleone G: IL-23/IL-17 axis in IBD. Inflamm Bowel Dis 16: 1808-1813, 2010.

10. Siakavellas SI and Bamias G: Role of the IL-23/IL-17 axis in Crohn's disease. Discov Med 14: 253-262, 2012.

11. Toussirot E: The IL23/Th17 pathway as a therapeutic target in chronic inflammatory diseases. Inflamm Allergy Drug Targets 1: $159-168,2012$

12. Imaeda H, Takahashi K, Fujimoto T, et al: Clinical utility of newly developed immunoassays for serum concentrations of adalimumab and anti-adalimumab antibodies in patients with Crohn's disease. J Gastroenterol 49: 100-109, 2014

13. Peyrin-Biroulet $L$ and Danese S: Stopping infliximab in Crohn's disease: still an ongoing STORI. Inflamm Bowel Dis 18: 2201-2202, 2012

14. Kilkenny C, Browne WJ, Cuthill IC, Emerson M and Altman DG: Improving bioscience research reporting: the ARRIVE guidelines for reporting animal research. PLoS Biol 8: e1000412, 2010.

15. Morris GP, Beck PL, Herridge MS, et al: Hapten-induced model of chronic inflammation and ulceration in the rat colon. Gastroenterology 96: 795-803, 1989.

16. Murthy SN, Cooper HS, Shim H, Shah RS, Ibrahim SA and Sedergran DJ: Treatment of dextran sulfate sodium-induced murine colitis by intracolonic cyclosporin. Dig Dis Sci 38: $1722-1734,1993$
17. Murano M, Maemura K, Hirata I, et al: Therapeutic effect of intracolonically administered nuclear factor kappa B (p65) antisense oligonucleotide on mouse dextran sulphate sodium (DSS)-induced colitis. Clin Exp Immunol 120: 51-58, 2000.

18. Wallace JL and Keenan CM: An orally active inhibitor of leukotriene synthesis accelerates healing in a rat model of colitis. Am J Physiol 258: G527-G534, 1990.

19. Guo L, Ye C, Hao X, et al: Carboxyamidotriazole ameliorates experimental colitis by inhibition of cytokine production, nuclear factor- $\kappa \mathrm{B}$ activation, and colonic fibrosis. J Pharmacol Exp Ther 342: 356-365, 2012.

20. Zingarelli B, Hake PW, Burroughs TJ, Piraino G, O'Connor M and Denenberg A: Activator protein-1 signalling pathway and apoptosis are modulated by poly(ADP-ribose) polymerase-1 in experimental colitis. Immunology 113: 509-517, 2004

21. Neurath MF, Fuss I, Kelsall BL, Stüber E and Strober W: Antibodies to interleukin 12 abrogate established experimental colitis in mice. J Exp Med 182: 1281-1290, 1995.

22. Strober W, Lúdvíksson BR and Fuss IJ: The pathogenesis of mucosal inflammation in murine models of inflammatory bowel disease and Crohn disease. Ann Intern Med 128: 848-856, 1998.

23. Torres MI, Garcia-Martin M, Fernandez MI, Nieto N, Gil A and Rios A: Experimental colitis induced by trinitrobenzenesulfonic acid: an ultrastructural and histochemical study. Dig Dis Sci 44: 2523-2529, 1999.

24. Lakatos PL and Lakatos L: Ulcerative proctitis: a review of pharmacotherapy and management. Expert Opin Pharmacother 9: 741-749, 2008.

25. Burger D and Travis S: Conventional medical management of inflammatory bowel disease. Gastroenterology 140: 1827-1837, 2011.

26. Magro F and Portela F: Management of inflammatory bowel disease with infliximab and other anti-tumor necrosis factor alpha therapies. BioDrugs 24: 3-14, 2010.

27. Mariette X, Matucci-Cerinic M, Pavelka K, et al: Malignancies associated with tumour necrosis factor inhibitors in registries and prospective observational studies: a systematic review and meta-analysis. Ann Rheum Dis 70: 1895-1904, 2011.

28. Deepak P, Sifuentes H, Sherid M, Stobaugh D, Sadozai Y and Ehrenpreis ED: T-cell non-Hodgkin's lymphomas reported to the FDA AERS with tumor necrosis factor-alpha (TNF- $\alpha$ ) inhibitors: results of the REFURBISH study. Am J Gastroenterol 108: 99-105, 2013

29. Huang R, Valerian BT and Lee EC: Laparoscopic approach in patients with recurrent Crohn's disease. Am Surg 78: 595-599, 2012.

30. Ivanov II, McKenzie BS, Zhou L, et al: The orphan nuclear receptor RORgammat directs the differentiation program of proinflammatory IL-17 ${ }^{+} \mathrm{T}$ helper cells. Cell 126: 1121-1133, 2006.

31. Ono Y, Kanai T, Sujino T, et al: T-helper 17 and interleukin-17-producing lymphoid tissue inducer-like cells make different contributions to colitis in mice. Gastroenterology 143: 1288-1297, 2012

32. Guan Q, Ma Y, Hillman CL, et al: Targeting IL-12/IL-23 by employing a p40 peptide-based vaccine ameliorates TNBS-induced acute and chronic murine colitis. Mol Med 17: 646-656, 2011.

33. De Nitto D, Sarra M, Cupi ML, Pallone F and Monteleone G: Targeting IL-23 and Th17-cytokines in inflammatory bowel diseases. Curr Pharm Des 16: 3656-3660, 2010.

34. Monteleone I, Pallone F and Monteleone G: Interleukin-23 and Th17 cells in the control of gut inflammation. Mediators Inflamm 2009: 297645, 2009.

35. Cho JH and Brant SR: Recent insights into the genetics of inflammatory bowel disease. Gastroenterology 140: 1704-1712, 2011.

36. Kurzeja M, Rudnicka L and Olszewska M: New interleukin-23 pathway inhibitors in dermatology: ustekinumab, briakinumab and secukinumab. Am J Clin Dermatol 12: 113-125, 2011.

37. Tzellos T, Kyrgidis A, Trigoni A and Zouboulis CC: Association of ustekinumab and briakinumab with major adverse cardiovascular events: An appraisal of meta-analyses and industry sponsored pooled analyses to date. Dermatoendocrinol 4: 320-323, 2012 